\title{
Homojen Dolgulu Sıkıştırma Ateşlemeli Motorlarda Enjeksiyon Zamanlamasının Motor Performansı ve Emisyon Oluşumuna Etkilerinin İncelenmesi
}

\author{
Müjdat FIRAT*1D, İsmail TÜRKBAY2 (D)
}

\author{
${ }^{1}$ Frrat Üniversitesi Teknik Eğitim Fakültesi Makine Eğitimi Bölümü, 23119, Elazığ \\ ${ }^{2}$ Fırat Üniversitesi Teknoloji Fakültesi Otomotiv Mühendisliği Bölümü, 23119, Elazığ
}

Geliş / Received: 27.09.2018, Kabul / Accepted: 9.10.2019

\section{$\ddot{O} z$}

Homojen dolgulu sıkıştırma ateşlemeli motorlar düşük NOx ve is emisyonları sağlaması sebebiyle umut verici çalışma alanları olarak görülmektedir. Özellikle dizel yakıtının püskürtme stratejilerinin değiştirilmesiyle yanmanın iyileştirilmesi hedeflenmektedir. Bu çalışma kapsamında dizel motor şartları altında homojen dolgulu sıkıştırma ateşlemeli bir motor için krank açısına (KA) bağlı farklı püskürtme zamanlaması araştırılmıştır. Çalışma AVL-FIRE sayısal yazılımı kullanılarak gerçekleştirilmiştir. Enjeksiyon üst ölü noktadan (ÜÖN) önce sırasıyla -150KA, -120KA, -90KA, -60KA ve -30KA'nda başlayan zamanlamalar için incelenmiştir. Tüm püskürtme zamanlamaları için enjeksiyon ÜÖN'dan 5KA sonra tamamlanmıştır. Çalışmalar sonucunda erken enjeksiyon zamanlamalarında yüksek sıcaklıklar ve kısmen yüksek NOx ve is emisyonları elde edilmiştir. Özellikle -90KA ve -60KA gibi geciken enjeksiyon zamanlamalarında daha düşük NOx ve is emisyonları elde edilmiştir. Fakat enjeksiyonun daha geç yapılması durumunda ise CO emisyonlarının arttığı gözlenmiştir.

Anahtar Kelimeler: Homojen dolgulu sıkıştırma ateşlemeli motorlar, Enjeksiyon zamanlaması, Yanma, Kirletici emisyonlar

\section{Investigation of the Effects of Injection Timing on Engine Performance and Formation of Emission in} Homogeneous Charge Compression Ignition Engines

\begin{abstract}
Homogeneous charge compression ignition engines are considered to be promising in studying areas due to their low NOx and soot emissions. Particularly, it is aimed to improve combustion by changing the injection strategies of diesel fuel. In this study, different spray timing for a homogeneous charge compression ignition engine was investigated under diesel engine conditions. Also, the AVL-FIRE numerical software was used in this study. Further, injection timing was examined at -150CA, -120CA, -90CA, -60CA and -30CA before the top dead center (BTDC). The injection was completed 5CA after TDC for all injection timings. The results showed that high temperatures, high NOx and soot emissions were obtained at early injection timing. Especially, lower NOx and soot emissions were obtained in the retarded injection timings such as -90KA and -60KA. However, in the case of late injection, $\mathrm{CO}$ emissions were increased.

Keywords: Homogeneous charge compression ignition (HCCI) engines, Injection timing, Combustion, Pollutant emissions
\end{abstract}

\section{Giriş}

Dizel motorların yüksek NOx ve is emisyonları son yıllarda gittikçe ağırlaşan emisyon standartları sebebiyle büyük bir sorun olarak görülmektedir. Bu kirletici emisyonların düşürülmesi için farklı yanma konseptleri üzerinde çalışmalar yürütülmektedir. Bu çalışmalardan en yaygını düşük sıcaklıklı bir yanma konsepti olan homojen dolgulu sıkıştırma ateşlemeli (HCCI) yanmadır. Yapılan çalışmalarda 
HCCI motorların daha düşük NOx ve is emisyonları sağladığı görülmektedir (Suzuki vd., 1997, Mathivanan vd., 2016). HCCI motorlar sağladıkları emisyon avantajlarının yanında bazı problemleri de birlikte getirmektedir. Bu problemlerden en önemlisi yanmanın kontrol edilmesidir (Yao vd., 2009). HCCI motorların yapısı gereği yanmanın başlamasını belirleyecek bir buji ya da ÜÖN bölgesinde bir enjeksiyon bulunmamaktadır. Dolayısıyla yanmanın kontrol edilmesi için araştırmacılar farklı yöntemler üzerinde çalışmalar yürütmektedir. $\mathrm{Bu}$ çalışmalardan birisi egzoz gazı geri dönüşüm (EGR) oranının kullanılmasıdır. Farklı oranlarda EGR kullanılmasıyla silindir içindeki ısı salınımı kontrol altına alınmaya çalışılmakta ve bu şekilde yanma kontrol edilmektedir (Lapuerta vd., 2000, Zheng vd., 2004). Ayrica HCCI motorlarda farklı gaz ve alkol yakıtların birlikte kullanılmasıyla yanmanın kontrol edilmesi ve tüm emisyon türlerinde iyileştirilmenin sağlanması araştırmacılar tarafından sıklıkla tercih edilen yöntemlerdir (Yousefzadeh ve Jahanian 2017, Jafarmadar vd., 2015, Kozarac vd., 2016). Gharehghani (2019) yaptığı çalışmada doğalgaz, etanol ve metanol yakıtlarının kullanıldığı HCCI bir motorda motor yükü limitlerinin belirlenmesini araştırmıştır. Deneysel olarak yürütülen çalışmada farklı giriş sıcaklıkları ve basınçları gibi parametreler kullanılarak farklı yakıtların motor yükü altında motor performansı ve emisyon oluşumuna etkileri incelenmiştir. Çalışma sonucunda doğalgazın yüksek yüklerde, yüksek giriş basınçlarında ve zengin karışım şartlarında en iyi sonucu verirken, etanol ve metanolun düşük giriş sıcaklıkları ve fakir karışım şartlarında daha iyi sonuç verdiği gözlenmiştir.

Bunun yanında bir diğer önemli çalışma grubu ise enjeksiyon stratejilerinin değiştirilmesidir. Farklı enjeksiyon zamanlamaları, farklı sayıda enjeksiyon uygulamaları ve diğer enjeksiyon parametrelerinin değiştirilmesi ile yanmanın kontrol edilmesi sağlanmaktadır (Khandal vd., 2017). Fang vd.(2012) deneysel olarak yürüttükleri çalışmada dizel motor şartları altında bir HCCI motorda pilot enjeksiyon uygulanmasına ilaveten EGR oranlarının değiştirilerek yanmanın kontrol edilmesini ve emisyonların düşürülmesini araştırmışlardır. Çalışma sonucunda pilot enjeksiyon miktarı arttıkça NOx emisyonlarının ciddi düşüş gösterdiği belirlenmiştir. Ayrıca düşük EGR oranlarında NOx emisyonlarının düştüğü gösterilmiştir. Coşkun vd. (2018) ethanol benzin karışımının yakıt olarak kullanıldığı bir HCCI motorda farklı enjeksiyon parametrelerinin yanma kontrolüne etkisini hem deneysel hem de stokastik reaktör modeli (SRM) kullanarak incelemişlerdir. Çalışmada emme zamanı boyunca birinci enjeksiyon yapılmış, sıkıştırma zamanı sonunda ise ikinci enjeksiyon gerçekleştirilmiştir. Çalışma sonucunda birinci enjeksiyonun yanma kontrolünde etkisiz olduğu vurgulanırken ikinci enjeksiyonun ve oranının yanma kontrolünde önemli bir strateji olduğu belirtilmiştir. Türkcan vd. (2018) deneysel ve sayısal olarak gerçekleştirdikleri çalışmada farklı oranlarda etanol-benzin ve metanolbenzin karışımlarının yakıt olarak kullanıldığı bir HCCI motorda iki kademeli enjeksiyonun etkisini araştırmışlardır. İki kademeli enjeksiyon stratejisinde birinci enjeksiyon emme zamanında ve sabit açılarda uygulanırken ikinci enjeksiyon ÜÖN yakınlarında ve değişen krank açılarında uygulanmıştır. Özellikle ikinci enjeksiyon zamanlamasının HCCI motorlarda yanmanın kontrol edilmesi için oldukça önemli olduğu gösterilmiştir. Çalışmada geciken enjeksiyon zamanlamalarının NOx emisyonlarını tüm yakıt karışımları için düşürdüğü, bunun 
yanında $\mathrm{CO}$ emisyonlarını kısmen artırdığ gözlenmiştir. Ghorbanpour ve Rasekhi (2013) sayısal olarak yürüttükleri ve deneysel olarak geçerliliğini sağladıkları çalışmada HCCI motorlarda emisyonları düşürmek ve verimi artırmak için parametrik bir çalışma yapmışlardır. Üst ölü noktadan 100KA önceden başlayarak 10KA farkla üst ölü noktadan 30KA önceye kadar püskürtme açısını değiştirmişlerdir. Enjeksiyon açısının değişiminin yanında bir diğer enjeksiyon parametresi olan enjeksiyon profili de bu çalışma kapsamında araştırılmıştır. Çalışmada erken püskürtmenin silindir içi basınç ve sıcaklığı artırırken NOx ve is emisyonlarını artırdığ1 gözlenmiştir. Ayrıca enjeksiyon profilinin HCCI yanması üzerine oldukça etkili olduğu gösterilmiştir.

İncelenen literatür 1şığında enjeksiyon stratejilerinin HCCI motorlarda yanmanın kontrol edilmesi ve kirletici emisyonların düşürülmesi için oldukça önemli olduğu görülmektedir. $\mathrm{Bu}$ çalışma kapsamın da ise HCCI direk enjeksiyonlu bir motorda enjeksiyon başlama açısı ve süresi değiştirilerek yanma kontrolü sağlanmaya çalışılmaktadır. Bu amaçla üst ölü noktadan 150KA önce başlayarak 30KA artışla üst ölü noktadan 30KA önceye kadar enjeksiyon başlama açısı değiştirilmiştir. Beş farklı enjeksiyon açısı ve süresi için çalışmalar tekrarlanarak belirlenen enjeksiyon stratejisinin motor performansı ve emisyon oluşumuna etkisi incelenmiştir. $\mathrm{Bu}$ şekilde değişen enjeksiyon açılarında ve ikinci bir enjeksiyona gerek duyulmadan HCCI motorlar için en uygun enjeksiyon açısı belirlenmeye çalışılmıştır. Elde edilen sonuçlar enjeksiyon stratejilerinin HCCI motorlar üzerindeki etkisini göstermekte olup literatürdeki eksikliği giderecek niteliktedir.

\section{Materyal ve Metot}

$\mathrm{Bu}$ çalışma kapsamında direk enjeksiyonlu HCCI bir motorda yanma fazının kontrol edilmesi ve düşük sıcaklıklı yanma sağlanarak kirletici emisyonların düşürülmesi için farklı enjeksiyon zamanlamaları incelenmiştir. Çalışma AVL-FIRE (AVL-FIRE User Guide, 2013) yazılımı kullanılarak sayısal olarak gerçekleştirilmiştir. Çalışmada dört silindirli dört zamanlı bir dizel motor HCCI şartları altında işletilmiştir. Çalışmada kullanılan motorun teknik özellikleri Tablo 1'de görülmektedir.

\begin{tabular}{ll}
\hline \multicolumn{2}{c}{$\begin{array}{c}\text { Tablo 1. Sayısal çalışmalarda kullanılan } \\
\text { motorun teknik özellikleri }\end{array}$} \\
\hline Motor Tipi & HCCI \\
\hline Silindir Sayısı & 4 \\
\hline Toplam Silindir Hacmi & $1.910 \mathrm{lt}$ \\
\hline Çap & $82 \mathrm{~mm}$ \\
\hline Strok & $90.4 \mathrm{~mm}$ \\
\hline Sıkıştırma Oranı & $18: 1$ \\
\hline Soğutma Şekli & Su Soğutmalı \\
\hline Enjektör Nokta Sayısı & 6 \\
\hline Enjektör Püskürtme & $140^{\circ}$ \\
Açısı & \\
\hline Enjektör Nozul çapı & $0.145 \mathrm{~mm}$ \\
\hline Maksimum Devir & $4000-4500$ devir/dakika \\
\hline Maksimum Tork & $280 \mathrm{Nm}$ \\
\hline $\begin{array}{l}\text { Maksimum } \\
\text { Devri }\end{array}$ & $2000 \mathrm{devir} /$ dakika \\
\hline Rölanti Devri & $850-900$ \\
\hline
\end{tabular}

$\mathrm{Bu}$ çalışma kapsamında, çözümlere geçilmeden önce incelenen motor şartlarında ağ yapısı test edilmiş ve ăg yapısından bağımsız çözüm elde edilmiştir. Ă̆ yapısından bağımsız çözümü elde etmek için farklı hücre sayılarında ağ yapısı kullanılarak sabit çalışma şartları için farklı çözümler elde edilmiştir. Çalışmada, çözümlenen kesit model (1/6 sektör model) için ve piston ÜÖN' da iken 12000, 20000, 50000, 80000, 120000 ve 180000 hücre sayıları için çözüm yapılmıştır. Çalışmada kullanılan model ve uygulanan ağ yapısı Şekil 1'de verilmiştir. 


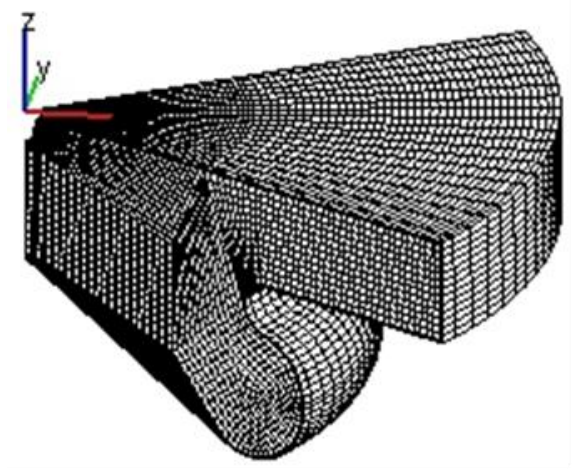

Şekil 1. Çalışmada kullanılan model ve ağ yapısı

Hücre sayının az olması çözüm kalitesini düşürürken fazla olması da çözüm kalitesine olumsuz yönde etki etmekte ve çözüm süresini aşırı şekilde uzatmaktadır. Bu çalışma sonucunda piston üst ölü noktada iken 80000 hücre sayılı çözüm kullanılmıştır. Çalışılan bir çok hücre sayısı için sonuçlar elde edilmiş ve belirlenen hücre sayısından sonra sonuçların değişmediği gözlenmiştir. Dolayısıyla sayısal çalışma süreside göz önünde bulundurularak ilgili hücre sayısı seçilmiştir. Piston alt ölü noktada iken çözüm modeli için yaklaşık 500000 hücre ile analizler yapılmıştır.

Çözümlerin yapılması için bir çok alt model sayısal yazılım aracılığıyla kullanılmıştır. Isıyı ve akışı yöneten süreklilik, momentum ve enerji denklemlerinin yanında, türbülanslı akışın çözümü için içten yanmalı motorlarda türbülans çözümlemeleri için literatürde sıklıkla tercih edilen k-(zeta)ל-f türbülans modeli kullanılmıştır (AVL-FIRE User Guide, 2013). Birinci ve ikinci atomizasyonun modellenmesi için WAWE model (Liu ve Ritz, 1993), 1s1-kütle transferi ve buharlaşma modeli olarak Dukowicz model (Dukowicz, 1997), sprey duvar etkileşimleri için Walljet model (Naber ve Reitz, 1988) ve silindir içi damlacık çarpışmaları için O'Rourke model (O’Rourke, 1989) kullanılmıştır.

Yanma olayının modellenmesi için alev yüzey yoğunluğu transport denklemleri ve karışım modelinin birlikte olduğu bir difüzyon yanma modeli olan ECFM-3Z model (Combustion Module, 2013) kullanılmıştır. Model AVLFIRE yazılımı tarafindan özellikle dizel benzeri yanma işlemlerinde kullanılmakla birlikte, ECFM modele kıyasla daha fazla kimyasal detay içerir. Dolayısıyla model otomatik ateşlemeli sistemlere oldukça uygundur. ECFM model üzerinde yapılan değişikliklerle birlikte bu model istenilen yanma çözümlemeleri için rahatlıkla kullanılabilmektedir. ECFM-3Z model $\mathrm{O}_{2}$, $\mathrm{N}_{2}, \mathrm{CO}_{2}, \mathrm{CO}, \mathrm{H}_{2}, \mathrm{H}_{2} \mathrm{O}, \mathrm{O}, \mathrm{H}, \mathrm{N}, \mathrm{OH}$ ve $\mathrm{NO}$ gibi kimyasal türlerin ortalama miktarları için transport denklemler çözmektedir. Modele ait denklemler aşağıdaki gibi sunulmaktadır.

$$
\frac{\partial \tilde{\rho}_{x}}{\partial t}+\frac{\partial \bar{\rho} \tilde{u}_{i} \tilde{y}_{x}}{\partial x_{i}}-\frac{\partial}{\partial x_{i}}\left(\left(\frac{\mu}{S c}+\frac{\mu_{t}}{S c_{t}}\right) \frac{\partial \tilde{y}_{x}}{\partial x_{i}}\right)=\dot{\bar{\omega}}_{x}
$$

Burada $\omega_{\mathrm{x}}$ yanma için kaynak terimini $\mathrm{y}_{\mathrm{x}}$ ise türler için kütlesel oranları ifade eder. $\mathrm{Bu}$ durumda taze gazlar ve yanmış gazlar iki

$$
\begin{aligned}
& \tilde{y}_{F u}^{u}=\frac{\widetilde{m}_{F u}^{u}}{\bar{m}^{b}}=\frac{\bar{\rho}_{F u}^{u}}{\bar{\rho}^{b}} \\
& \widetilde{y}_{F u}^{b}=\frac{\widetilde{m}_{F u}^{b}}{\bar{m}}=\frac{\bar{\rho}_{F u}}{\bar{\rho}}
\end{aligned}
$$


Model içerisinde bir transport denklem

kullanılarak yanmamış gazlar

hesaplanmaktadır.

$$
\frac{\partial \tilde{\rho}_{F u}^{u}}{\partial t}+\frac{\partial \bar{\rho} \tilde{u}_{i} \tilde{y}_{F u}^{u}}{\partial x_{i}}-\frac{\partial}{\partial x_{i}}\left(\left(\frac{\mu}{S c}+\frac{\mu_{t}}{S c_{t}}\right) \frac{\partial \tilde{y}_{F u}^{u}}{\partial x_{i}}\right)=\bar{\rho} \tilde{\dot{S}}_{F u}^{u}+\bar{\omega}_{F u}^{u}
$$

Denklemde kullanılan $\mathrm{S}$ taze gazlar içerisindeki yakıtın buharlaşmasını ifade eden kaynak terimdir. Bu şekilde dizel yanmasına daha uygun bir yanma modeli elde edilmiş olmaktadır.

Ayrıca NO emisyonlarının hesaplanması için genişletilmiş Zeldovic mekanizması ve is emisyonlarının hesaplanması için kinetik is modeli bu çalışma kapsamında tercih edilmiştir (Emission Module, 2013). İlgili mekanizmalar NO ve is emisyonlarının elde edilmesi için literatürde sıklıkla kullanılan ve AVL FIRE tarafindan da önerilen mekanizmalardır.

Sayısal çalışmalar belirlenen test motorunda sabit 2000d/d motor devrinde, sabit yakıt tüketimi $(2.9 \mathrm{mg} /$ çevrim), sabit sıkıştırma oranı (18.0) ve yaklaşık 300KA analiz süresi altında incelenmiştir. Çalışmanın yürütülmesi bir HCCI motorun farklı enjeksiyon zamanlamalarını içermektedir. Farklı enjeksiyon açıları kullanılarak yakıtın silindir içerisinde kalma süresi değiştirilmiş ve yanma fazı kontrol edilmeye çalışılmıştır. Bu maçla erken enjeksiyon sayılacak açılardan başlanarak üst ölü noktaya doğru farklı enjeksiyon açıları taranmış ve HCCI şartları oluşturulmuştur. $\mathrm{Bu}$ amaçla belirlenen 5 farklı durum ve durumları ifade eden detaylı enjeksiyon parametreleri Tablo 2'de verilmiştir.

Tablo 2. Çalışma parametreleri

\begin{tabular}{lll}
\hline Durum 1 & $-150 \mathrm{KA}$ & Enjeksiyon ÜÖN'dan 150KA önce başlar ve ÜÖN'dan 5KA sonra biter. \\
\hline Durum 2 & $-120 \mathrm{KA}$ & Enjeksiyon ÜÖN'dan 120KA önce başlar ve ÜÖN'dan 5KA sonra biter. \\
\hline Durum 3 & $-90 \mathrm{KA}$ & Enjeksiyon ÜÖN'dan 90KA önce başlar ve ÜÖN'dan 5KA sonra biter. \\
\hline Durum 4 & $-60 \mathrm{KA}$ & Enjeksiyon ÜÖN'dan 60KA önce başlar ve ÜÖN'dan 5KA sonra biter. \\
\hline Durum 5 & $-30 \mathrm{KA}$ & Enjeksiyon ÜÖN'dan 30KA önce başlar ve ÜÖN'dan 5KA sonra biter. \\
\hline
\end{tabular}

\section{Bulgular}

HCCI motorlarda yanmanın kontrol edilmesinin en önemli yöntemlerinden birisi yakıtın farklı zamanlarda yanma odasına gönderilmesidir. Bu şekilde yanma başlangıcının kontrol edilmesi ve düşük sicaklikta yanma durumu sağlanmaya çalışılmaktadır. Bu çalışmada HCCI bir motorda, yakıtın farklı enjeksiyon zamanlarında yanma odasına püskürtülmesi durumları için yanma ve emisyon analizleri yapılmıştır. Çalışma içerinde üst ölü noktadan önce farklı beş krank açısında (ÜÖN'dan 150,120,90,60 ve $30 \mathrm{KA}$ önce) yakıt yanma odasına gönderilmiştir. Dolayısıyla aynı miktarda yakıtın üst ölü noktadan önce gönderilmesine bağlı olarak 
yanma karakteristikleri ve emisyonlar üzerine etkileri analiz edilmiştir.

Şekil 2'de krank mili açısına bağlı olarak silindir içi ortalama basınç değişimleri farklı enjeksiyon zamanları için verilmiştir. Yakıt erken krank açılarında yanma odasına gönderilirse yanmanın daha erken başladığı ve silindir içi basıncın en yüksek durumlara ulaştığı görülmektedir. $\mathrm{Bu}$ durum yakıt hava karışımının oldukça homojen olması ve yakıt ve oksijenin yüksek oranda buluşmasının bir sonucu olarak görülmektedir. Yakıtın enjeksiyon zamanlaması ÜÖN'ya yaklaştıkça silindir içi basınç kademeli olarak düşmektedir. Fakat özellikle -60KA'sinda yapilan enjeksiyonda basıncın bu düşüşü devam ettirmeyip kismen yükseldiği görülmektedir.

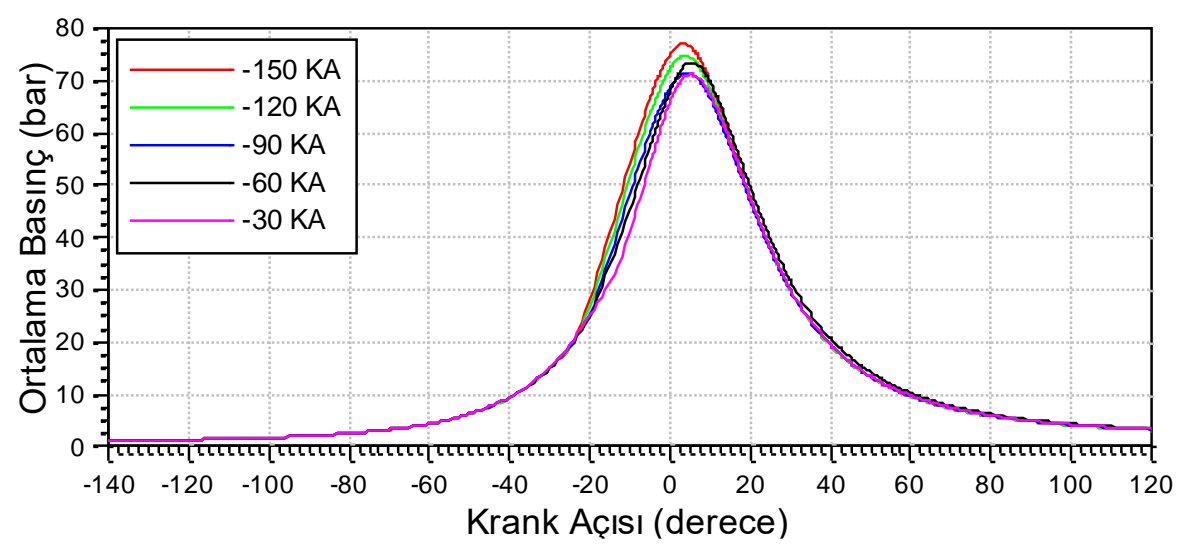

Şekil 2. Farklı enjeksiyon zamanlarında silindir içi basıncın değişimi

Şekil 3'de farklı enjeksiyon zamanlamasına bağlı olarak silindir içi ortalama sıcaklık değişimi görülmektedir. HCCI yanma şartlarında özellikle düşük sıcaklıklı yanma şartlarının sağlanması önemlidir. Şekilde görüldüğü üzere tüm enjeksiyon zamanlamaları için dizel şartlarına göre daha düşük sıcaklıklı yanma elde edilmiştir. Enjeksiyonun erken yapılması durumunda silindir içi sıcaklığın en yüksek olduğu daha sonra ilerleyen enjeksiyon zamanlamasında azaldığı görülmektedir. Ayrıca erken enjeksiyon zamanlamasında yanmanın daha erken başlamasının sonucu olarak
ÜÖN'dan önce sıcaklık hızlıca yükselmiş daha sonra hızlıca düşmüştür. Fakat özellikle -60KA'sında sicaklık yükselmesinin yaklaşık olarak ÜÖN'ya çok yakın bir noktada gerçekleştiği ve devam eden süreçte daha yavaş azaldığ 1 görülmektedir. $\mathrm{Bu}$ enjeksiyon şartında yanmanın en ideal noktada yoğun olarak gerçekleştiği düşünülmektedir. Enjeksiyonun -30KA'sında yapıldığ 1 durumda ise yanmanın oldukça geç başladığı ve sıcaklığında hızlı düştüğü görülmektedir. 




Şekil 3. Farklı enjeksiyon zamanlarında silindir içi sıcaklığın değişimi

Farklı enjeksiyon zamanlamaları için 1sı salınım oranları Şekil 4'de görülmektedir. Enjeksiyon zamanlaması erken olduğu durumlarda (-150KA, -120KA) 1s1 salınımın oldukça erken başladığı görülmektedir. $\mathrm{Bu}$ durumlar için 1S1 salınımının büyük bölümünün ÜÖN'dan çok önce gerçekleştiği gözlenmiştir. Geç enjeksiyon zamanlamasında (-30KA) ise 1s1 salınımın çok geç ve hızlı bir şekilde meydana geldiği görülmektedir. Bu durum yanma odası içerisinde yükselen sıcaklığın bir sonucu olarak görülmektedir.

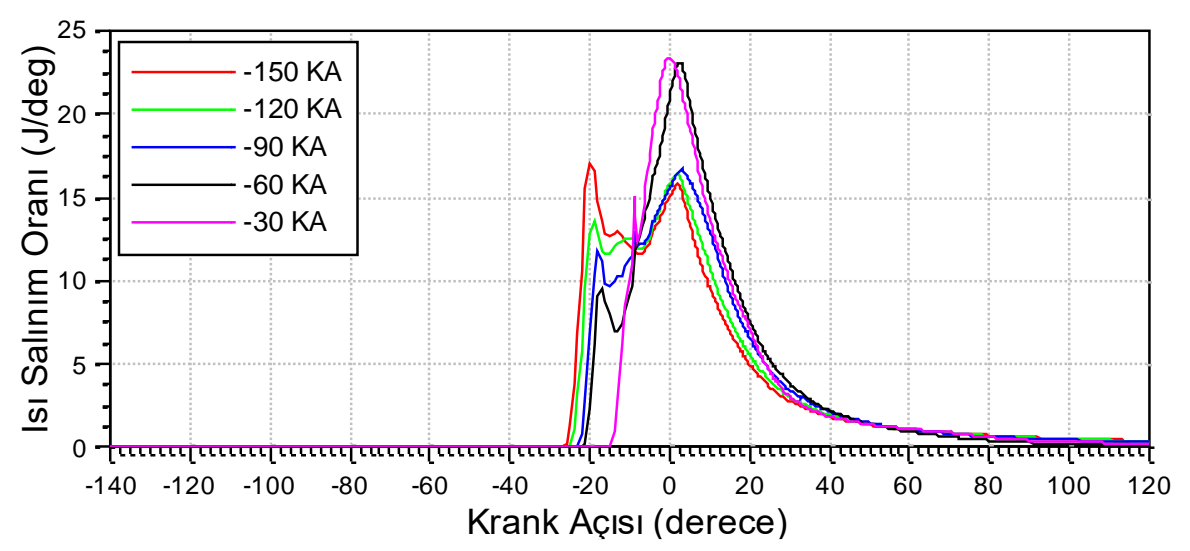

Şekil 4. Farklı enjeksiyon zamanlarında ısı salınım oranının değişimi

$\mathrm{Bu}$ çalışmanın parametrelerini gösteren yakıt enjeksiyonunun krank açısına bağlı değişimi ve durumda buharlaşan yakıt miktarı Şekil 5'de görülmektedir. Yakıtın yanma odası içerinde kaldığı süreye bağlı olarak buharlaşma hızı ve miktarının değişimi, tam yanmanın gerçekleşmesi ve düşük emisyonların elde edilmesi bakımından oldukça önemlidir. Özellikle erken enjeksiyonda sürenin uzun olmasından dolayı daha fazla yakıtın buharlaştığı ve yanmanın daha erken başladığı anlaşılmaktadır. Geç enjeksiyon durumunda ise yakıtın buharlaşması için yeterli sürenin bulunmadığı bu şekilden anlaşılmaktadır. 


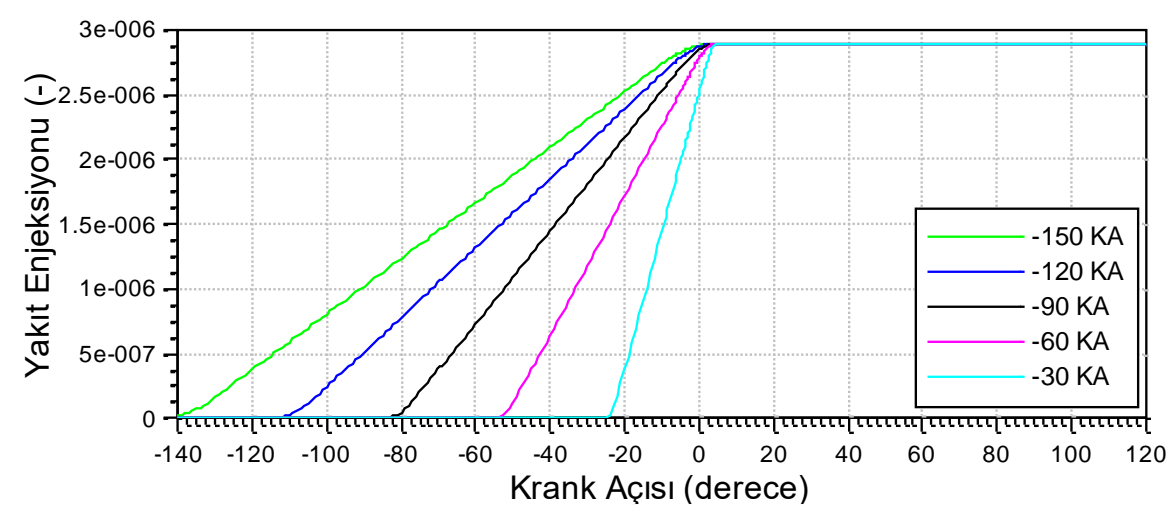

a)

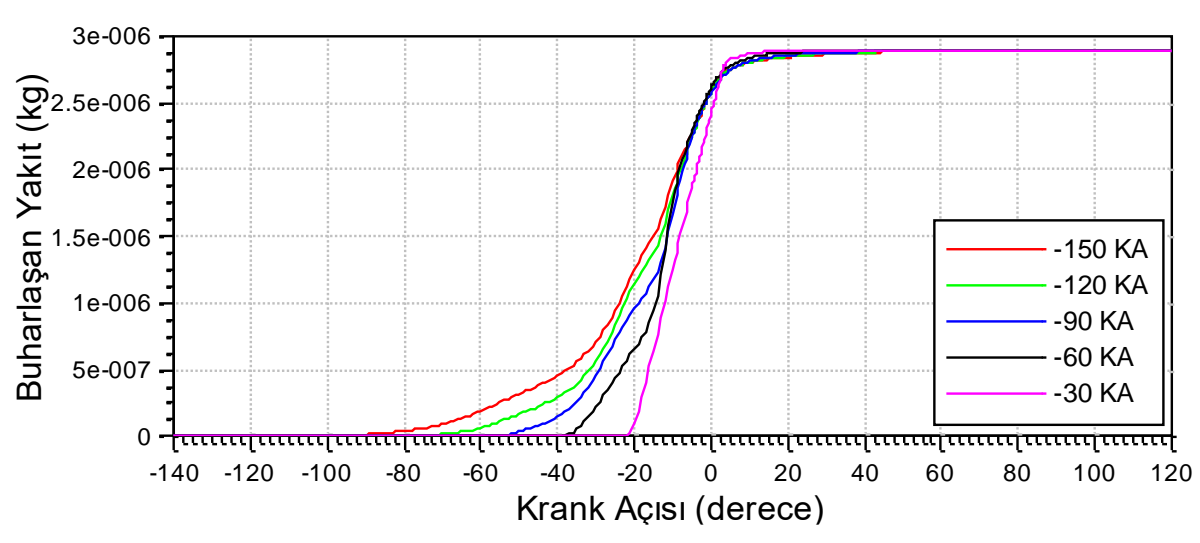

b)

Şekil 5. Farklı enjeksiyon zamanlarında yakıt püskürtme ve buharlaşma durumlarının değişimi

Şekil 6'da farklı enjeksiyon zamanlamaları için NOx ve İs emisyonlarının değişimi görülmektedir. NOx emisyonları yüksek sıcaklıklı yanma olayının doğal bir sonucudur. Bu sebeple uygulanan HCCI yanma stratejisinde genel olarak düşük yanma sıcaklıkları ve buna bağlı olarak düşük NOx emisyonları elde edilmiştir. Çalışma parametrelerinde ise enjeksiyon zamanlaması geciktikçe NOx emisyonlarının azaldığı görülmektedir. $\mathrm{Bu}$ sonuçlar silindir içi sıcaklık sonuçlarını da doğrular niteliktedir. Fakat -60KA durumunda sıcaklık değişimine de bağlı olarak başlangıçta düşük NOx emisyonu elde edilirken ÜÖN'ya yaklaştıkça sıcaklığın çok hızlı yükselmesi sonucu kısmen yüksek NOx emisyonları elde edilmiştir. Şekil 6 (b) de görülen is emisyonları ise kötü yanma ve silindir içerinde meydana gelen alev sönmelerinin bir sonucudur. Görüldüğü üzere erken enjeksiyon zamanlarında yüksek olan is emisyonları enjeksiyon zamanları geciktikçe kademeli olarak düşmektedir. Dolayısıyla en düşük is emisyonları sirasiyla -60KA ve -90KA enjeksiyon zamanlarında elde edilmiştir. $\mathrm{Bu}$ duruma ters bir sonuç olarak ise -30KA görülmektedir. Is1 salınımın ve yakıt buharlaşmasının oldukça gecikmesi ve yanmanın kötü olması neticesinde püskürtülen yakıtın oksijen ile buluşmasının zorlaştığı ve buna bağlı is emisyonlarının arttığı görülmektedir. 


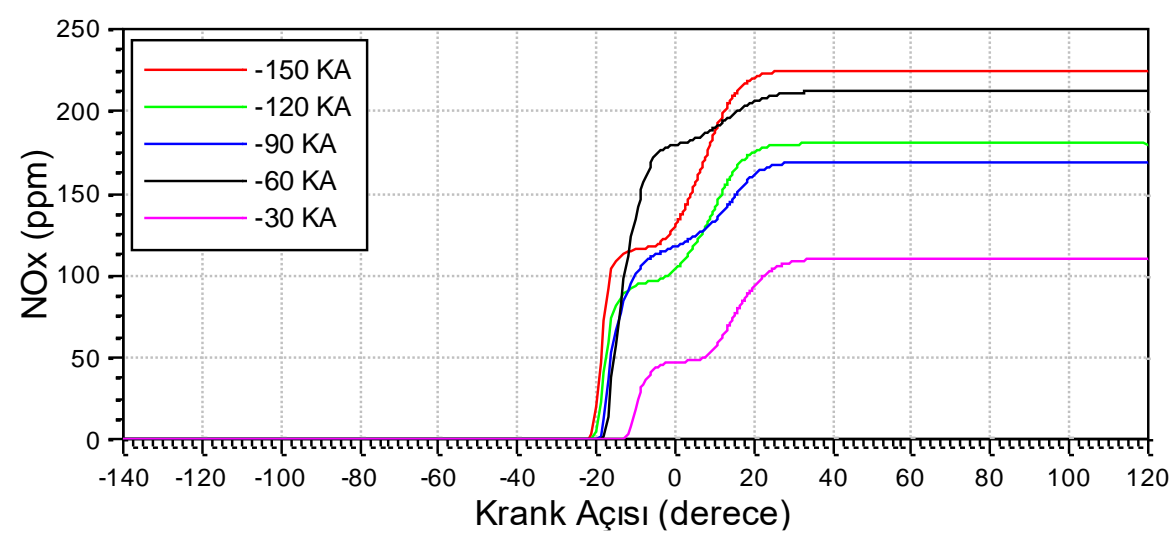

a)

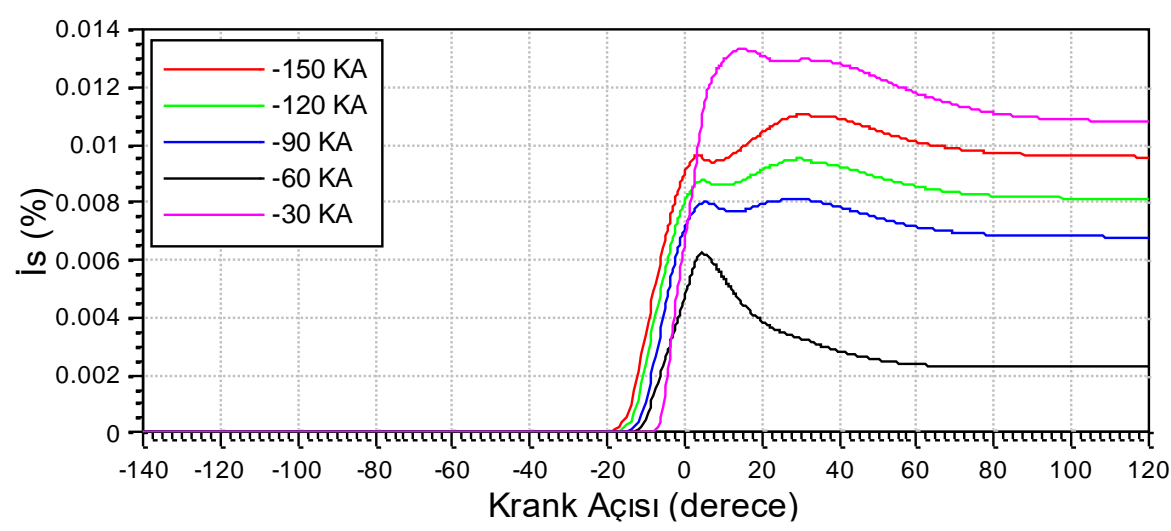

b)

Şekil 6. Farklı enjeksiyon zamanlarında NOx ve is emisyonlarının değişimi

Yanma sonu emisyonlarında önemli olan bir diğer grup ise $\mathrm{CO}$ ve $\mathrm{CO}_{2}$ emisyonlarıdır. Yanma kalitesi gösteren bu sonuçlar zararlı emisyonlar olarak da özellikle incelenmelidir. CO emisyonları kötü yanma ürünü olup istenmeyen emisyonlardandır. Şekil 7(a)'da görüldüğü üzere -30KA'da enjeksiyon yapıldığ 1 durumda oldukça yüksek $\mathrm{CO}$ emisyonu elde edilmiștir. Aynı zamanda en düşük CO emisyonu -60KA durumunda gözlenmektedir. $\mathrm{CO}$ emisyonları azaldıkça yanma mekanizmalarının doğal bir sonucu olarak tam yanma ürünü olan $\mathrm{CO}_{2}$ emisyonları artmaktadır. Dolayısıyla Şekil 7(b)'de en yüksek $\mathrm{CO}_{2}$ emisyonu -60KA da görülmektedir. 


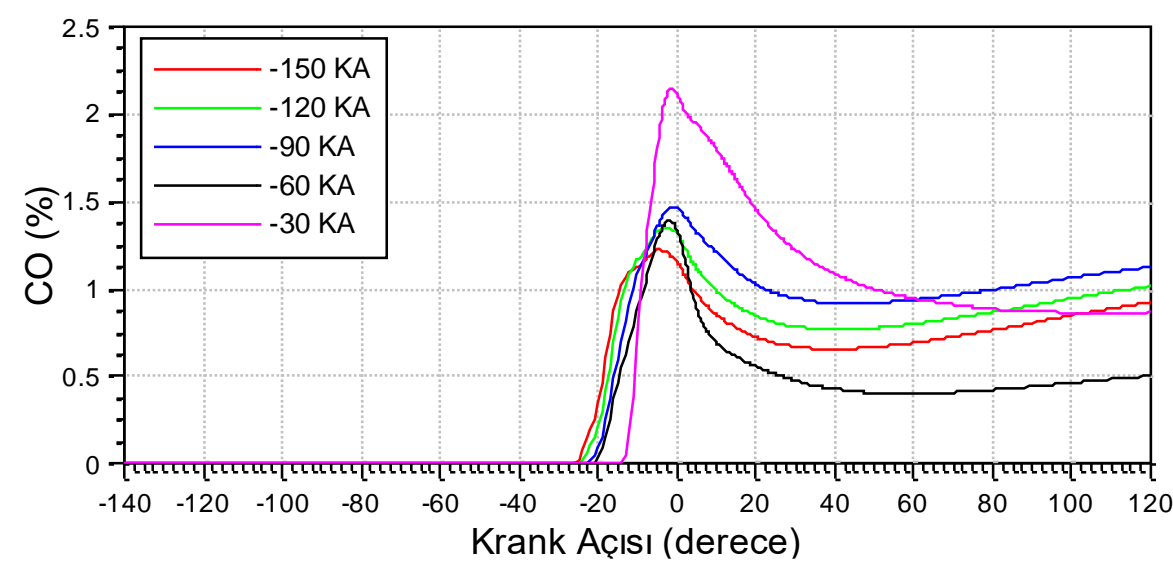

a)

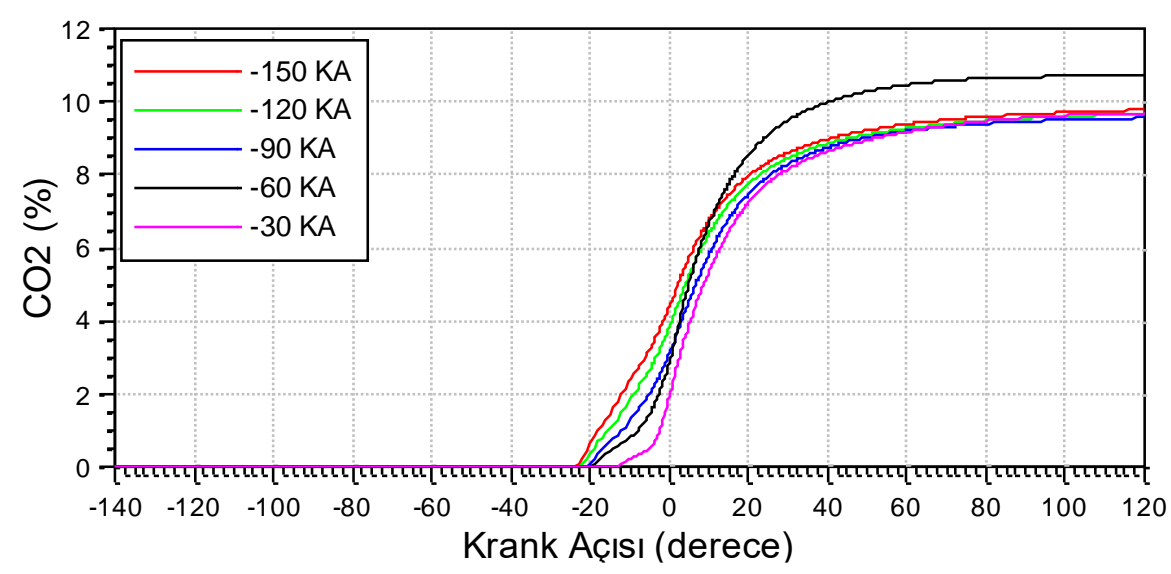

b)

Şekil 7. Farklı enjeksiyon zamanlarında $\mathrm{CO}$ ve $\mathrm{CO}_{2}$ emisyonlarının değişimi

Şekil 8'de -10KA için sıcaklık dağılımları verilmiştir. Bu şekilde yanma odas içerinde oluşan yapıları görülmektedir. Ana alev cephesinin piston çanağ 1 ile silindir kapağ arasında meydana geldiği görülmektedir. Özellikle erken enjeksiyon durumunda ana alev cephesi yanında piston çanağ 1 içerisinde farklı noktalarda küçük alev yapılarının olduğu görülmüştür. -90KA ve -
60KA durumunda ise yanmanın kısmen daha düşük sıcaklıklarda başladığ gözlenmiştir. Geç enjeksiyon zamanlamasında ise yakıt enjeksiyonunun henüz bittiği ve yakıtın buharlaşmak üzere olduğu aynı zamanda hızlı bir sıcaklık yükselişi görülmektedir. 

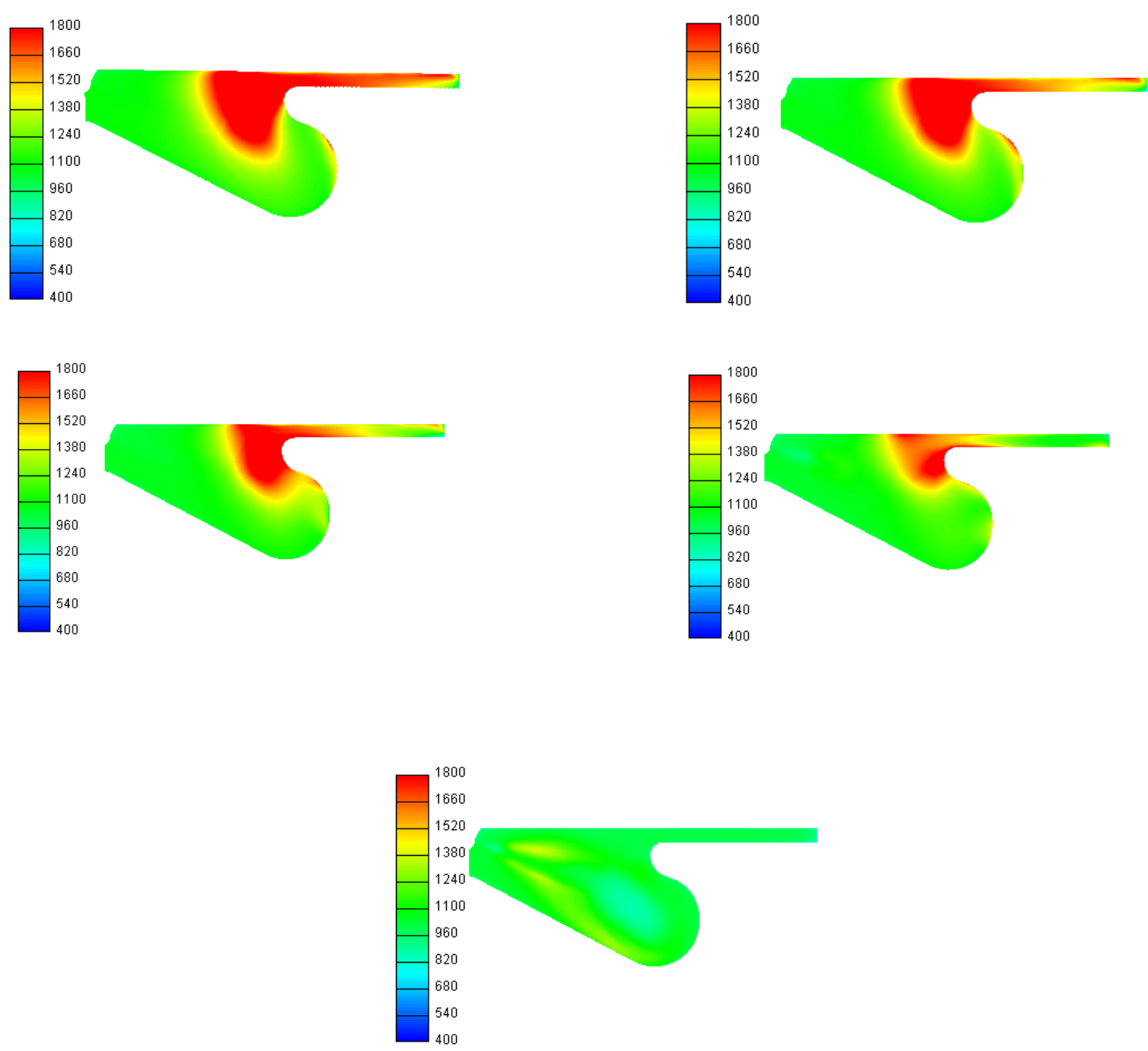

Şekil 8. ÜÖN'dan -10KA önce sıcaklık dağılımı

Şekil 9'da pistonun ÜÖN'da olmas1 durumu görülmektedir. Tüm enjeksiyon zamanlamaları için yanma başlamış ve devam etmektedir. Yanma odalarında farklı sıcaklık bölgeleri, çatallaşan alev yapıları ve farklı bölgelerde yüksek sıcaklık bölgeleri bu KA için açıkça görülmektedir. Geç enjeksiyon durumunda bir önceki sonuçlarda yakıtın buharlaşmasından hemen sonra yanmanın çok hızlı başladığı bu şekilden anlaşılmaktadır.

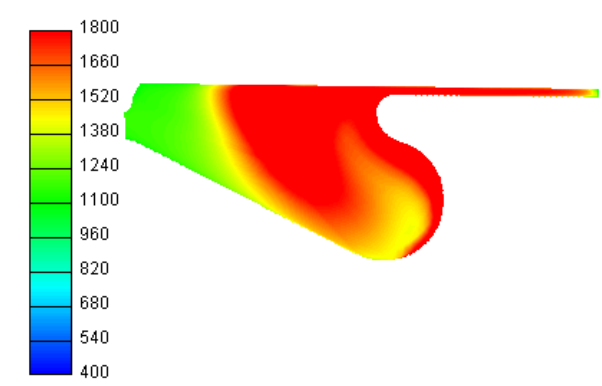

$-150 \mathrm{KA}$

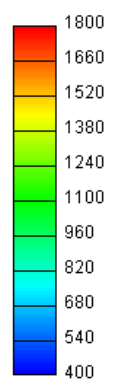

$-120 \mathrm{KA}$ 

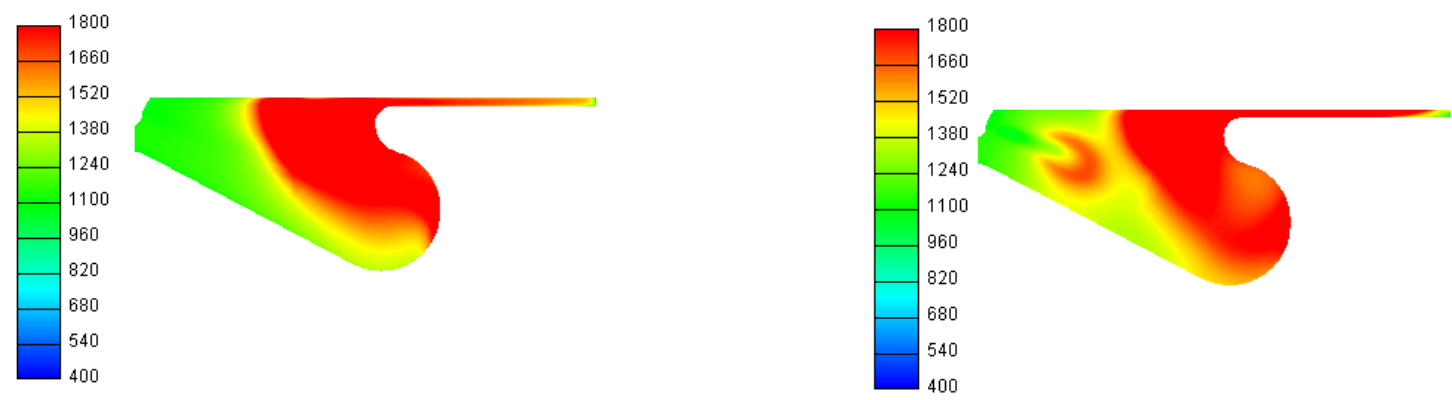

-90KA

$-60 \mathrm{KA}$

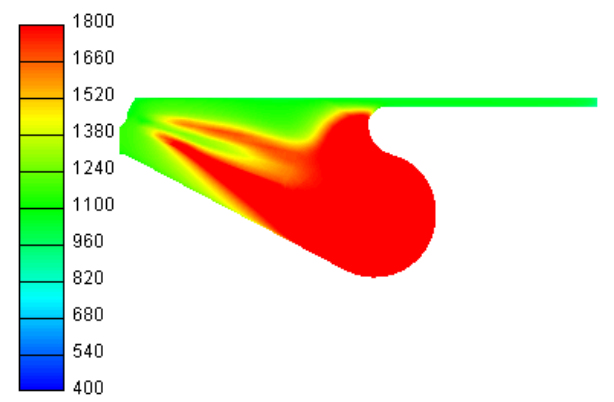

$-30 \mathrm{KA}$

Şekil 9. ÜÖN'da sıcaklık dağılımı

Şekil 10 pistonun ÜÖN'yı geçtikten 10KA sonrası için yanma odası içerisinde sıcaklık dağılımlarını göstermektedir. Tüm enjeksiyon zamanlamaları için alev cephesinin hemen hemen birleştiği ve yanma odası içerisinde yayıldığı görülmektedir. Özellikle silindir merkezinde ve uzak silindir cidarlarına

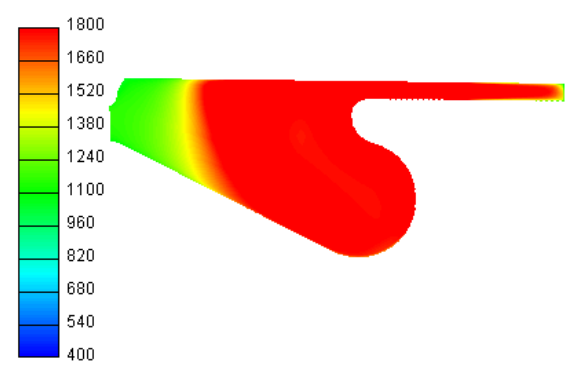

$-150 \mathrm{KA}$ henüz alev cephesi ulaşamamıştır. Şekilde en üniform ilerlemenin -60KA enjeksiyon zamanlamasında olduğu görülmektedir. Geç enjeksiyon zamanlaması için ise daha önceki şekilde piston çanağında başlayan alev cephesinin silindir içerisinde ilerlemeye başladığı fakat henüz çok küçük olduğu elde edilen önemli bir sonuçtur.

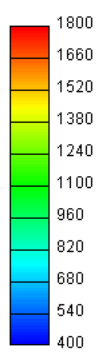

$-120 \mathrm{KA}$ 

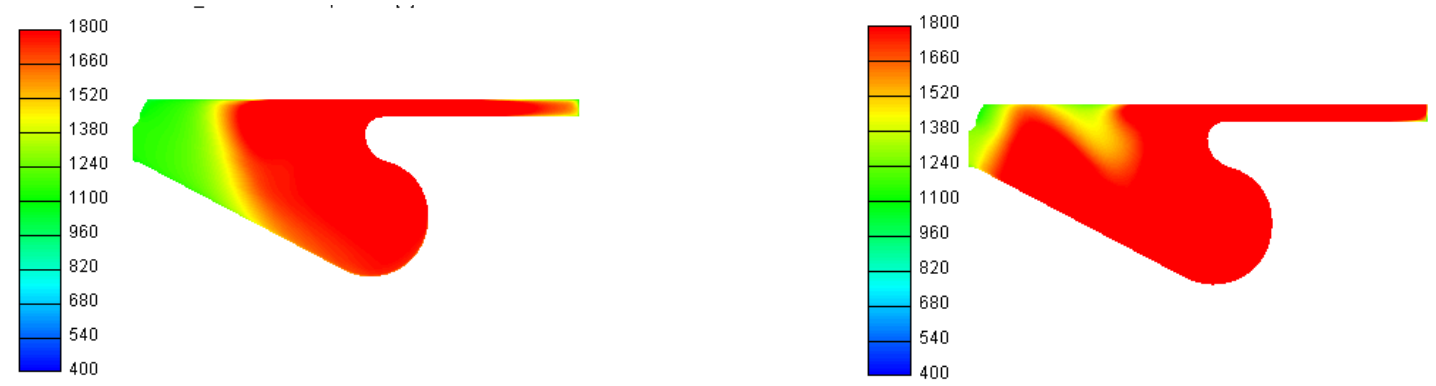

$-90 \mathrm{KA}$

$-60 \mathrm{KA}$
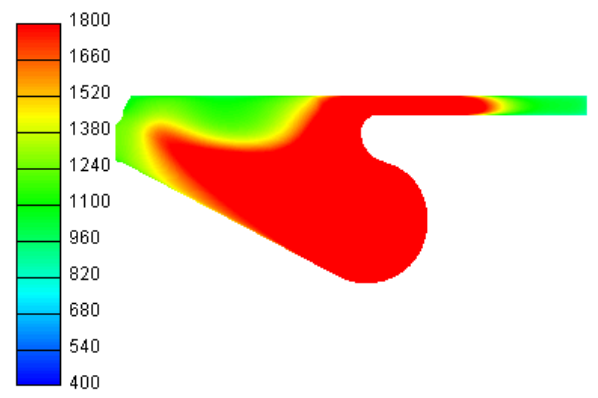

$-30 \mathrm{KA}$

Şekil 10. ÜÖN'dan 10KA sonra sıcaklık dağılımı

\section{Sonuç ve Tartışma}

$\mathrm{Bu}$ çalışmada HCCI bir motorda farklı enjeksiyon zamanlamalarının motor performans1, yanma karakteristikleri ve emisyon oluşumlarına etkilerinin sayısal olarak incelenmesi gerçekleştirilmiştir. Bilindiği üzere HCCI yanma stratejisi düşük sıcaklıklı yanmanın ve buna bağlı olarak daha düşük kirletici emisyonların arzulandığ 1 yanma konseptidir. HCCI motorlarda yanmanın kontrol edilebilmesi ve istenilen sonuçların elde edilmesi için ise enjeksiyon stratejileri özel önem taşımaktadır. $\mathrm{Bu}$ çalışmada AVL FIRE sayısal yazılımı kullanılarak üç boyutlu olarak tasarlanan bir dizel motor HCCI şartlarına adapte edilmiştir. Oluşturulan HCCI motor üzerinde farklı enjeksiyon zamanlamaları denenerek yanma karakteristikleri ve emisyon oluşumları elde edilmiştir. Çalışmadan elde edilen sonuçlara göre;

- Yakıt erken krank açılarında yanma odasına gönderilirse yanmanın daha erken başladığ 1 ve silindir içi basıncin en yüksek durumlara ulaştı̆̆1 görülmüştür. $\mathrm{Bu}$ durum yakıt hava karışımının oldukça homojen olmasının, ayrica yakıt ve oksijenin yüksek oranda buluşmasının bir sonucu olarak görülmektedir.

- Yakit enjeksiyonunun erken yapılması durumunda silindir içi sıcaklığın en yüksek olduğu daha sonra ilerleyen enjeksiyon zamanlamalarında azaldı görülmüştür.

- Yakıt enjeksiyon zamanlamasinın erken olduğu durumlarda (-150KA, -120KA) 1sı salınımın oldukça erken başladığı görülmüştür. Bu durumlar 
için 1S1 salınımının büyük bölümünün ÜÖN'dan çok önce gerçekleştiği gözlenmiştir.

- Enjeksiyon zamanlaması geciktikçe NOx emisyonlarının azaldığ gözlenmiştir.

- Erken enjeksiyon zamanlarında yüksek olan is emisyonları enjeksiyon zamanları geciktikçe kademeli olarak düşmektedir. Dolayısıyla en düşük is emisyonları sirasiyla -60KA ve $-90 \mathrm{KA}$ enjeksiyon zamanlarında elde edilmiştir.

- -30KA'da enjeksiyon yapıldığ 1 durumda oldukça yüksek $\mathrm{CO}$ emisyonu elde edilmiştir. Aynı zamanda en düşük $\mathrm{CO}$ emisyonu 60KA durumunda gözlenmektedir.

- Çalışma sonucunda elde edilen sonuçlar enjeksiyon açısının yanma üzerine etkilerini ayrıntılı olarak göstermektedir. $\mathrm{Bu}$ çalışmaların özellikle farklı motor yük şartları altında deneysel olarak tekrarlanması HCCI motorlar için çalışma aralıkların belirlenmesini kolaylaştıracaktır.

\section{Teşekkür}

Yazarlar, finansal desteklerinden dolayı TEKF 15.11 Nolu proje için Furat Üniversitesi Bilimsel Araştırma Projeleri Koordinasyon Birimi Başkanlığı'na ve yazılım desteklerinden dolayı AVL firmasına teşekkür eder.

\section{Kaynaklar}

AVL-FIRE User Guide, 2013.

Coskun, G. Demir, U. Soyhan, H. S. Turkcan, A. Ozsezen A. N. and Canakci, M. 2018. "An experimental and modeling study to investigate effects of different injection parameters on a direct injection
HCCI combustion fueled with ethanolgasoline fuel blends", Fuel , 215, 879-891.

Combustion Module, 2013. AVL FIRE user Manual v.2013. 2, 2013.

Dukowicz, J.K. 1997. Quasi-steady droplet change in the presence of convection. informal report Los Alamos Scientific Laboratory, LA7997-MS.

Emission Module, 2013. AVL FIRE user Manual v.2013. 2, 2013.

Fang, Q. Fang, J. Zhuang, J. and Huang, Z. 2012. "Influences of pilot injection and exhaust gas recirculation (EGR) on combustion and emissions in a HCCI-DI combustion engine", Applied Thermal Engineering, 48, 97-104.

Gharehghani, A. 2019. "Load limits of an HCCI engine fueled with natural gas, ethanol, and

Methanol", Fuel, 239, 1001-1014.

Ghorbanpour, M., Rasekhi R. 2013. “A parametric investigation of HCCI combustion to reduce emissions and improve efficiency using a CFD model approach", Fuel, 106, 157-165.

Jafarmadar, S. Nemati, P. and Khodaie, R. 2015. "Multidimensional modeling of the effect of Exhaust Gas Recirculation (EGR) on exergy terms in an HCCI engine fueled with a mixture of natural gas and diesel", Energy Conversion and Management, 105, 498-508.

Khandal, S.V. Banapurmath, N.R. Gaitonde V.N. and Hiremath, S.S. 2017. "Paradigm shift from mechanical direct injection diesel engines to advanced injection strategies of diesel homogeneous charge compression ignition (HCCI) engines- A comprehensive review", Renewable and Sustainable Energy Reviews, 70, 369-384.

Kozarac, D. Taritas, I. Vuilleumier, D. Saxena S. and Dibble, R. W. 2016. "Experimental and numerical analysis of the performance and exhaust gas emissions of a biogas/n-heptane fueled HCCI engine", Energy, 115, 180-193. 
Lapuerta, M. Hernandez, J.J. and Gimenez, F. 2000. "Evaluation of exhaust gas recirculation as a technique for reducing diesel engine NOx emissions", Proc Inst Mech Eng Part D J Autom Eng, 214, 85-93.

Liu, A.B. Reitz, R.D. 1993. "Modeling the Effects of Drop Drag and Break-up on Fuel Sprays". SAE 930072.

Mathivanan, K. Mallikarjuna J. M. and Ramesh A. 2016. "Influence of multiple fuel injection strategies on performance and combustion characteristics of a diesel fuelled HCCI engine - An experimental investigation", Experimental Thermal and Fluid Science, 77, 337-346.

Naber, J.D. Reitz, R.D. 1988. "Modeling Engine Spray/Wall Impingement." SAE880107.

O'Rourke, P.J. 1989. "Statistical Properties and Numerical Implementation of a Model for Droplet Dispersion in Turbulent Gas" J. Comput. Physics 83, 1989.

Suzuki, H. Koike, N. Ishii H. and Odaka, M. 1997. "Exhaust purification of diesel engines by homogeneous charge with compression ignition part1: experimental investigation of combustion and exhaust emission behavior under pre-mixed homogeneous charge compression ignition method", SAE Paper No. 970313.

Turkcan, A. Altinkurt, M. D. Coskun, G. and Canakci, M. 2018. "Numerical and experimental investigations of the effects of the second injection timing and alcoholgasoline fuel blends on combustion and emissions of an HCCI-DI engine", Fuel, 219, 50-61.

Yao, M.F. Zheng, Z.L. and Liu, H.F. 2009 "Progress and recent trends in homogeneous charge compression ignition (HCCI) engines", Prog. Energ. Combust. Sci., 35, 398-437.

Yousefzadeh, A. and Jahanian, O. 2017. "Using detailed chemical kinetics 3D-CFD model to investigate combustion phase of a CNG-HCCI engine according to control strategy requirements", Energy Conversion and Management , 133, 524-534.

Zheng, M. Reader, G.T. and Hawley, J.G. 2004. "Diesel engine exhaust gas recirculation - a review on advanced and novel concepts". Energy Convers Manage, 45, 883-900. 